\title{
MNP
}

\section{Navigate Uncertainty}

Everyone has a role to play to help others through this

pandemic. Ours is providing insights and strategies to guide you and your business to move forward. 


\section{CORPORATE-OWNED LIFE INSURANCE: Primer for Professionals}

By Kerry Smith, CPA, CA

Life insurance is an essential tool in traditional estate planning. It provides liquidity at the time of an individual's death and offers peace of mind knowing their family is taken care of in case something should happen to them.

But did you know life insurance isn't just for emergencies? Structured properly, life insurance can also be an essential tax planning tool and provide significant benefits today - not just after your death.

\section{TYPES OF INSURANCE}

Life insurance generally falls into two categories - term and permanent.

Term Insurance

Term insurance is just that: insurance for a fixed period; typically 5,10 or 20 years. Every year of the term has a set premium, with a fixed amount of insurance available during that time. When the term ends, the policy and insurance coverage expire. Due to its time-bound and fixed nature, term insurance tends to be inexpensive.

\section{Permanent Insurance}

Permanent insurance provides guaranteed coverage for life. The policy pays out the death benefit, regardless of your age or changes to your health, assuming you pay your premiums. In addition to the underlying insurance, permanent insurance policies include an investment component.

Although permanent insurance policies require premium payments for life, they are generally structured so the investment component of the policy funds the premium payments after a fixed term. This means you might only need to make premium payments for 10,15 , or 20 years. This is similar to a term insurance policy; however, the coverage continues for life. The self-funding nature of these policies makes them a solid method of creating wealth in the long term.

\section{TAX BENEFITS OF CORPORATE-OWNED LIFE INSURANCE}

Cost to Acquire Policy

Using a corporation to purchase insurance allows for faster accumulation of wealth. By using corporate dollars instead of personal funds to pay for the policy, the same level of income can purchase significantly more insurance. If you were to buy insurance personally, you would need to pay personal tax on the money you're taking out of the corporation and would therefore have less cash available to put towards the insurance policy.

\section{Tax Free Accumulation}

Structured properly, most permanent life insurance policies in Canada are known as "exempt policies." Any investment income earned inside these policies grows tax free.

Also, investments within an insurance policy tend to outperform those within a standard investment account on an after-tax basis because of the personal and corporate tax rates on investment income.

\section{Tax Efficient Distributions}

When the insured individual dies, the corporation receives the tax-free death benefit - including both the base amount and any accumulated growth in the policy's investment component.

The amount by which the death benefit exceeds the adjusted cost basis of the policy is added to the corporation's capital dividend account. The corporation can pay this out to the remaining shareholders or estate tax free, creating an extremely tax-efficient outcome.

\section{Leveraged Insurance Options}

If you were to cancel an insurance policy at any time, the insurer returns an amount of cash to you. This is known as the cash surrender value (CSV). Most policies include a guaranteed CSV and a variable component based on the growth in the investment part of the policy.

Since the CSV is a liquid and secure asset, financial institutions are typically happy to use the CSV as security for a loan. Some financial institutions will lend up to 100 percent of CSV. As the policy may be more than you intend to leave to your estate, you could access the value of the policy while you are alive by borrowing and using the policy as collateral.

With leveraging, you can access the wealth accumulated within an insurance policy during your lifetime, not just after your death.

There are several ways to structure the borrowings. The corporation can borrow against the policy to either reinvest the funds or make shareholder distributions. In some situations, and subject to addressing possible shareholder benefit issues arising from the use of a corporate asset to secure a personal loan, the individual shareholder may be able to borrow against the corporate-owned policy to either finance their lifestyle or investment needs. Depending on the use of the funds, interest on the borrowed money and a portion of the annual premium payments might even be tax deductible.

\section{IS CORPORATE-OWNED LIFE INSURANCE RIGHT FOR YOU?}

Corporate-owned life insurance is an incredibly effective estate, tax and liquidity planning tool if used properly. The type, amount and structure of insurance needed vary significantly depending on personal needs and circumstances. Contact an MNP Tax Advisor today to learn whether corporateowned life insurance could help you reach your personal and professional goals.

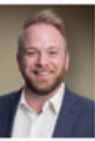

Kerry Smith, CPA, CA, is a Partner within MNP's Professional Services team. For more information, contact Kerry at 604.685 .8408 or kerry.smith@mnp.ca

Visit our COVID-19 Business Advice Centre (2) MNP.ca/COVID-19

ACCOUNTING > CONSULTING > TAX 


\section{Are you getting the right advice?}

Are you confident the financial advice you're receiving is truly physician-focused?

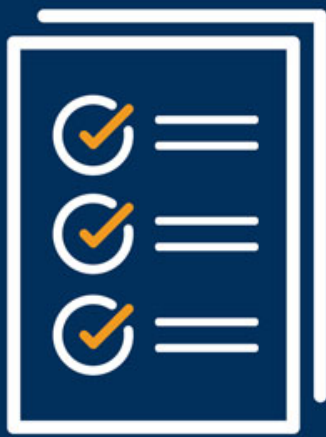

Over the last few months, we've helped thousands of physicians and their families across Canada manage the impact of the pandemic on their finances and start planning for the "new normal."

Join more than $39,000^{*}$ Canadian physicians and discover the difference it makes to get the right advice.

\section{Visit md.ca/rightadvice}

"As of May 13,2020.

MD Financial Management provides financial products and services, the MD Family of Funds and investment counselling services through the MD Group of Companies. For a detailed list of these companies, visit md.ca.

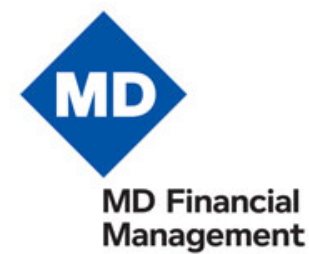




\section{RECOGNIZING HS}

\section{DO YOU RECOGNIZE PATIENTS WITH HIDRADENITIS SUPPURATIVA (HS)?}

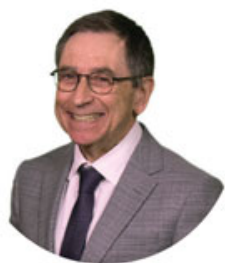

DR. NEIL SHEAR

Head of Dermatology, Sunnybrook Hospital

HS is a chronic, painful, inflammatory skin disease that affects $1-4 \%$ of the general adult population. It is characterized by boils usually occurring where certain sweat glands are located, such as under the breasts, buttocks, and inner thighs."

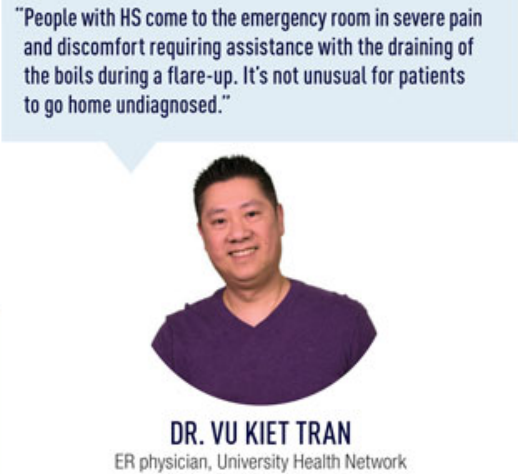

"People with HS come to the emergency room in severe pain the boils durir

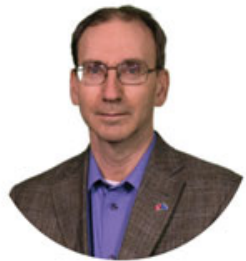

DR. RALPH GEORGE Associate Professor, University of Toronto, Division of General Surgery

There is currently no cure for HS. Early diagnosis and proper management is important for a patient's quality of life. The first step for those with $\mathrm{HS}$ is to speak to their dermatologist to get an accurate diagnosis."

\section{NEW North American HS Guidelines NOW AVAILABLE}

To learn more about HS from these specialists and the new guidelines, go to www.RecognizingHS.com/CJEM

\section{WHEN YOU SEE THESE LESIONS, DO YOU SUSPECT HS?}

DO YOU ASK ABOUT RECURRENCE?

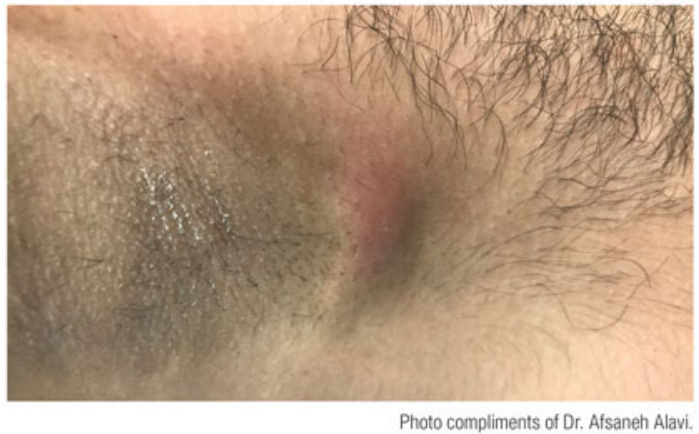

ASSESSING PATIENTS WITH RECURRENT BOILS

Most HS cases can be recognized with high reliability by the presence of 3 main features: ${ }^{1 \cdot 3}$

1. Typical lesions: nodules, sinus tracts, abscesses, scarring

2. Typical anatomical location: axilla, groin, genitals, under the breasts, others (perianal, neck, abdomen, buttocks)

3. Relapses and chronicity: $\geq 2$ times per 6 months

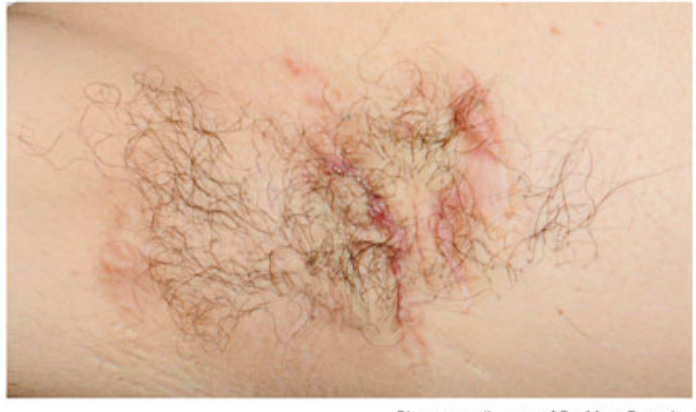

Photo compliments of Dr. Marc Bourcier.

Questions to ask your patients with suspected HS:

1. Have you had outbreaks of boils during the last 6 months?

2. Where were the boils and how many did you have?

To confirm an HS diagnosis, please refer your patient to a dermatologist.

References: 1. Zouboulis CC, et al European S1 guideline for the treatment of hidradenitis suppurativa/acne inversa. JEADV2015:29:619-44. 2. Lockwood SJ, et al. Diagnostic workup. In: Kimball AB, Jemec GBE, eds. Hidradenitis Suppurativa: A Disease Primer. Cham, Switzerland: Springer; 2016:27-37. 3. Poli F, et al Clinical presentation. In: Jemec GBE, Revuz J, Leyden JJ, eds. Hidradenitis Suppurativa. Berlin, Germany: Springer; 2006:11-24. 


\section{Are you getting the right advice?}

\author{
When it comes to financial \\ advisors, you want someone \\ who really understands \\ the world you live in.
}

The COVID-19 pandemic has caused stress and uncertainty for all Canadians and has hit physicians hard. For those working with or near COVID-19 patients, there's the worry about getting sick or passing the virus to their families. For others, there's the reduced practice hours and loss of income because of physical distancing. And to top it off, there was the precipitous drop in the markets.

As a physician or member of a physician household facing these extra stresses and challenges, you need specialized advice.

You give specialized advice. So do we. Physicians fall into a unique category. and we provide advice through all the stages of your life and career.

During these times, MD Financial Management (MD) can help you:

- navigate the government support available to physicians and their families

- assess the impacts of increased/decreased billings on your short- and long-term plans, and adjust as needed

- claim the tax deductions available to you and your staff while working from home

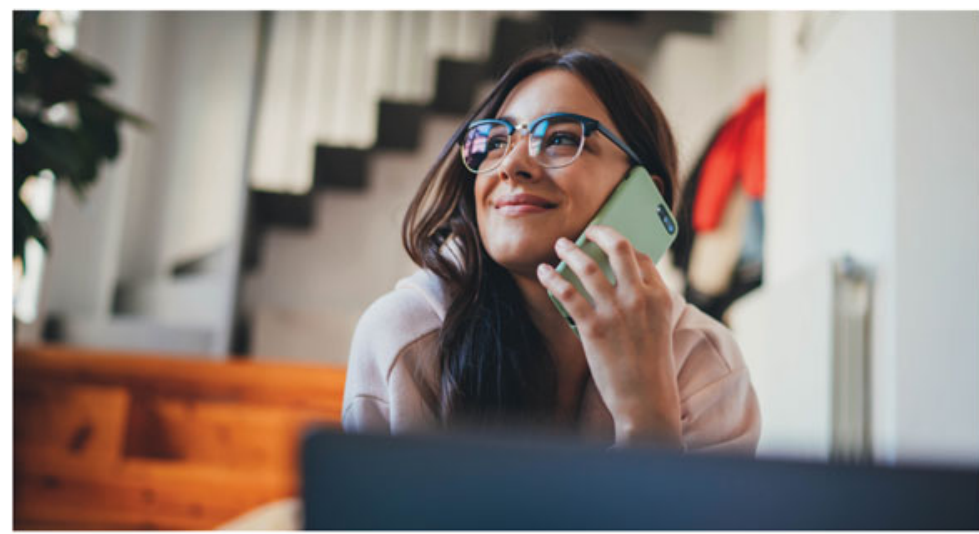

- plan for the tax-efficient transfer of your assets, the way you want. upon your death

- access life insurance to protect your family and the wealth you leave behind

\section{Financial planning throughout your life}

Are you confident the financial advice you're receiving is truly physician-focused?

$M D$ is the only national firm with 50-plus years of service exclusively to physicians. We work with more than

39,000 physicians $^{1}$ so we understand the challenges that you face and can anticipate your needs.

All MD clients - physicians and their family members - can benefit from MD's services, whether it's financial planning, tax planning, investments, insurance, medical practice incorporation, or estate and trust planning. An MD Advisor* can work with specialists in these other areas to help you with more complex strategies.

As you grow your investment assets, you'll want to ensure you're using the various types of accounts (RRSPS,

TFSAs, etc.) and optimizing their performance, especially if you also invest through your corporation.
Tax legislation also keeps changing, so it's important to be aware of the impact of each choice, particularly if you're an incorporated physician.

Our relationship with Scotiabank delivers scale, resources and capital that we've never had access to before. We're now able to leverage their tools, technologies and strategic partnerships to deliver a better client experience and make it easier for you to do business with your MD Advisor.

MD and Scotiabank are here to help you and your family whenever we can, whether you are a client or not. Scotiabank has also introduced flexible measures to help alleviate the financial hardship physicians may be experiencing as a result of COVID-19.

Physicians, along with nurses, paramedics and other healthcare personnel, can get front-of-the-line service when they call Scotiabank contact centres, to ensure they receive the dedicated service they deserve right now.

Learn more about MD and getting the right advice at md.ca/rightadvice. 


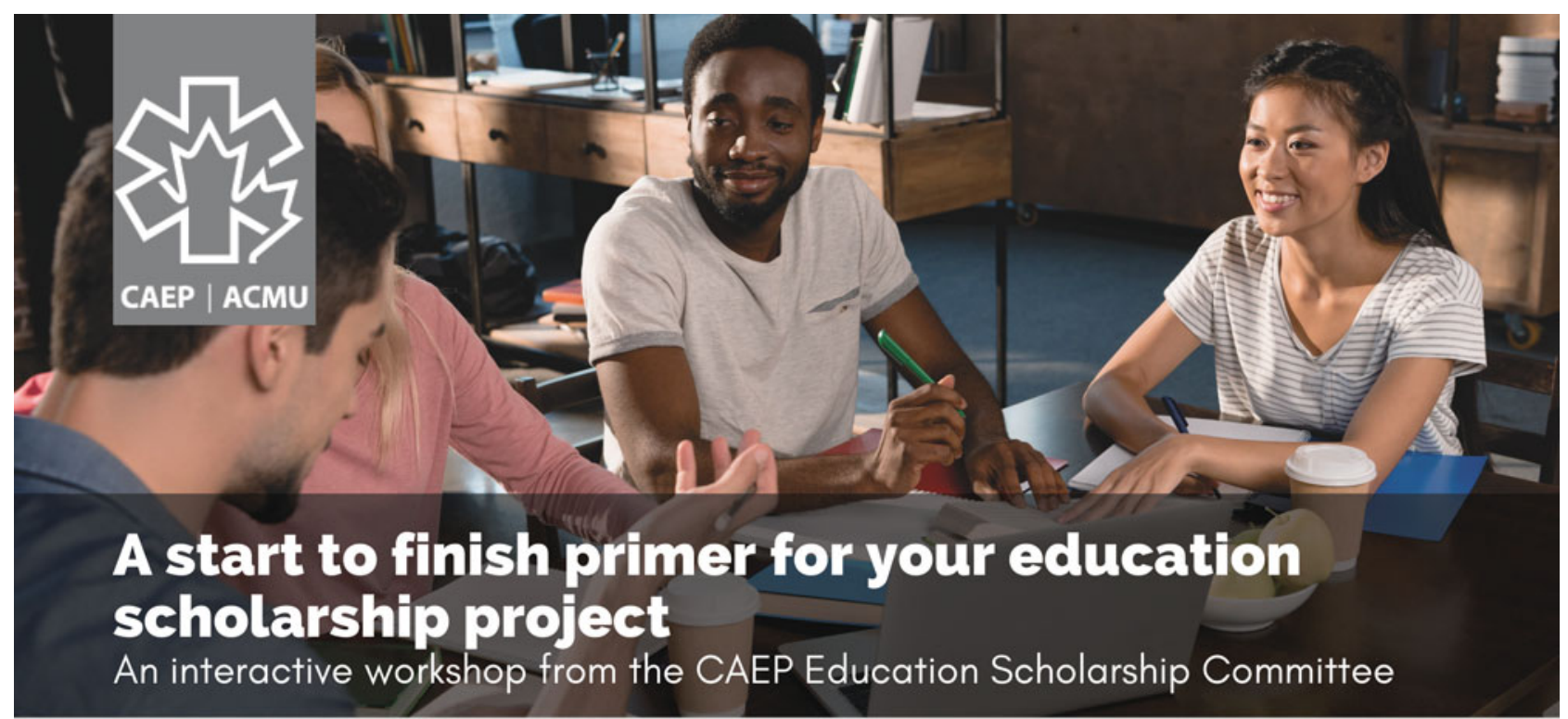

Thursday, October 15, 2020 from 1600-1900 (PST) / 1900-2200 (EST)

Zoom with breakout rooms

\section{TARGET AUDIENCE}

Medical students, residents, and faculty pursuing medical education scholarship projects who need guidance to bring their project from concept to completion

\section{SCHEDULE}

PART I: Research Question \& Methods

- Cutting Edge Medical Education - What's hot right now and what's not!

- Developing a great education research question - the Problem Gap Hook heuristic

- What research methodology will best answer your question?

- Think Pair Share in Break-Out Rooms

PART II: Collaborators, Ethics \& Funding

- Making the dream team - who are the key collaborators for your project?

- Does your project require ethics?

- Show me the Money - Does your project need grant funding and where to find it

- Think Pair Share in Break-Out Rooms

\section{PART III: Dissemination}

- Abstract Deadlines - Which medical education conference are you targeting?

- What do you mean it has to be in a journal and alternative ways to disseminate your work

- 1st Draft Worst Draft - Writing up your manuscript, team rules of editing \& responding to 'revise and resubmit

- 'Think Pair Share in Break-Out Rooms

- Wrap-up

\section{REGISTRATION \& DETAILS}

caep.ca/em-community/academic-section/education-committee/a-start-to-finishprimer-for-your-education-scholarship-project 


\section{CAEP 2021 ABSTRACT COMPETITION}

\section{ABSTRACT SUBMISSION CATEGORIES}

Research

Education Research

Education Innovation

Quality Improvement \& Patient Safety

\section{ABSTRACT AWARDS}

Only CAEP members will be considered for abstract awards. Join CAEP or renew your membership today.

CAEP 2021 will take place June 13-16 in Winnipeg, Manitoba. Successful abstract presenters are responsible for their own expenses and conference registration.

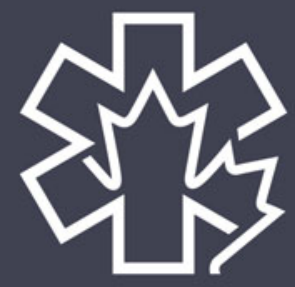

\section{CAEP | ACMU}

Competition Opens: Wednesday, October 28, 2020 Competition Closes: Friday, December 11, 2020 Competition Details: caep.ca/research/abstract-competition-2/ 